\title{
Small-Angle and Ultrasmall-Angle Neutron Scattering (SANS/USANS) Study of New Albany Shale: A Treatise on Microporosity
}

\author{
Jitendra Bahadur, ${ }^{\dagger}$ Andrzej P. Radlinski, ${ }^{\ddagger}$, Yuri B. Melnichenko, ${ }^{* \dagger}$ Maria Mastalerz, ${ }^{\S}$ \\ and Arndt Schimmelmann \\ ${ }^{\dagger}$ Biology and Soft Matter Division, Oak Ridge National Laboratory, Oak Ridge, Tennessee 37831-6393, United States \\ ${ }^{\ddagger}$ Queensland Micro and Nanotechnology Centre, Griffith University, Nathan 4111, Brisbane, Australia \\ ${ }^{\S}$ Indiana Geological Survey, ${ }^{\nabla}$ Department of Geological Sciences, Indiana University, Bloomington, Indiana 47405-2208, \\ United States
}

\section{Supporting Information}

ABSTRACT: Small-angle neutron scattering (SANS) and ultrasmall-angle neutron scattering (USANS) techniques were applied to study the microstructure of several New Albany shales of different maturity. It has been established that the total porosity decreases with maturity and increases somewhat for post-mature samples. A new method of SANS data analysis was developed, which allows the extraction of information about the size range and number density of micropores from the relatively flat scattering intensity observed in the limit of the large scattering vector $Q$. Macropores and significant number of mesopores are surface fractals, and their structure can be described in terms of the polydisperse spheres (PDSP) model. The model-independent Porod invariant method was employed to estimate total porosity, and the results were compared with the PDSP model results. It has been demonstrated that independent evaluation of incoherent background is crucial for accurate interpretation of the scattering data in the limit of large Q-values. Pore volumes estimated by the $\mathrm{N}_{2}$ and $\mathrm{CO}_{2}$ adsorption, as well as via the mercury intrusion technique, have been compared with those measured by SANS/USANS, and possible reasons for the observed discrepancies are discussed.

\section{INTRODUCTION}

Porosity is the key structural factor that defines the ability of shale to store natural gas and oil. In shales, both mineral and organic matter usually contributes to the total porosity. Each of the existing porosimetry methods covers only a limited range of pore sizes, and the characterization of samples with wide pore size distribution generally requires application of several characterization methods (see Figure 1). The most common techniques that are used are helium porosimetry and low-pressure nitrogen $\left(\mathrm{N}_{2}\right)$ and carbon dioxide $\left(\mathrm{CO}_{2}\right)$ adsorption, as well as mercury intrusion porosimetry (MIP). Several recent studies have used these techniques to understand pore size distribution in shales. ${ }^{1-4}$ Small-angle and ultrasmall-angle neutron scattering (SANS/ USANS) techniques have also been employed recently to study the structure of coals ${ }^{5,6}$ and shales. ${ }^{2,3,7,8}$

When comparing the sample porosity and pore size distribution determined using different techniques, it is important to remember that each of the techniques is based on different principles; therefore, some differences in the results may be expected. For example, in our recent paper, ${ }^{4}$ we directly compared porosity and pore size distribution data from gas adsorption and MIP techniques. As a rule, MIP provides information about the specific pore throat sizes that allow access to pore volumes. Pore throat size is an important parameter because it correlates with rock permeability and porosity. ${ }^{9,10}$ There are several reasons to expect method-specific differences in pore size distribution and pore volume data from gas adsorption and MIP techniques when studying shales. Because of the small size of $\mathrm{He}$ and $\mathrm{CO}_{2}$ gas molecules, they can access small nanosized pores and, hence, are ideal for probing microporosity. In contrast, mercury cannot penetrate micropores easily, and the necessity of using very high injection pressures $(\sim 380 \mathrm{MPa})$ may cause artifacts, because of distortion of the matrix structure, opening initially closed pores, and deforming the porous matrix. ${ }^{11,12}$ In addition, MIP measures the size of pore throats, but not the actual pore body.

Our comparative study demonstrated that, despite differences between the gas sorption and MIP techniques, the measured pore volume and pore size distribution often qualitatively agree with each other. ${ }^{4}$ This further suggests that these techniques are valuable and complementary for the structural characterization of shales, especially because each technique provides unique and specific information: MIP evaluates the size of pore throats, whereas gas adsorption assesses the distribution of pore body sizes.

Early SANS studies of coal and shale did not consider the small and relatively flat scattering background usually observed at the large $Q$-values. This approach was caused by intrinsic complexity involved in decoupling the incoherent background and scattering contribution from small micropores. ${ }^{7,8,13,14}$ Generally, to simplify the analysis of SANS data, the Qindependent scattering intensity at large $Q$-values was subtracted from the experimental scattering profile. Such a procedure is fully justified if the population of micropores is not significant.

Received: October 1, 2014

Revised: December 15, 2014

Published: December 17, 2014 


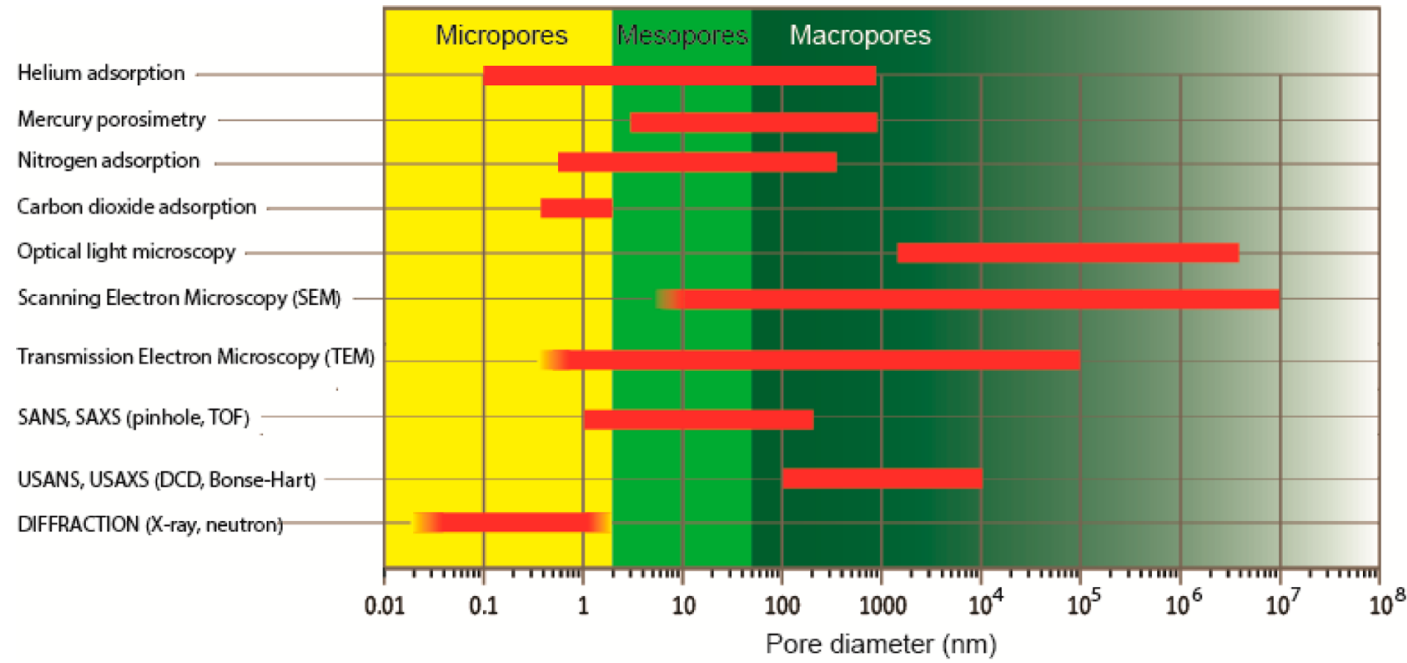

Figure 1. Comparison of the ranges of pore sizes that can be probed using various types of gas adsorption methods, optical microscopy, electron microscopy, neutron and X-ray scattering.

Table 1. Volume Proportion of Minerals Present in Shale Samples and Volume-Average Matrix Density Calculated for Five Shales ${ }^{a}$

\begin{tabular}{|c|c|c|c|c|c|c|c|c|c|c|c|}
\hline & \multirow[b]{2}{*}{ density $\left(\mathrm{g} / \mathrm{cm}^{3}\right)$} & \multicolumn{2}{|c|}{$472-1$} & \multicolumn{2}{|c|}{ MM4 } & \multicolumn{2}{|c|}{ NA2 } & \multicolumn{2}{|c|}{ IL-5 } & \multicolumn{2}{|c|}{ IL-1 } \\
\hline & & (wt \%) & (vol \%) & (wt \%) & (vol \%) & (wt \%) & (vol \%) & (wt \%) & (vol \%) & (wt \%) & (vol \%) \\
\hline quartz & 2.65 & 20 & 20.48 & 35 & 30.84 & 36 & 34.53 & 32 & 31.31 & 26 & 25.42 \\
\hline carbonates & 2.80 & 51 & 49.42 & 0 & 0 & 1 & 0.91 & 26 & 24.08 & 10 & 9.25 \\
\hline albite & 2.61 & 8 & 8.32 & 9 & 8.05 & 13 & 12.66 & 6 & 5.96 & 29 & 28.8 \\
\hline orthoclase & 2.6 & 2 & 2.09 & 0 & 0 & 1 & 0.98 & 4 & 3.99 & 18 & 17.94 \\
\hline pyrite & 5.0 & 2 & 1.09 & 1 & 0.47 & 3 & 1.53 & 2 & 1.04 & 9 & 4.66 \\
\hline clays & 2.63 & 16 & 16.51 & 42 & 37.29 & 41 & 39.61 & 26 & 25.64 & 2 & 1.97 \\
\hline TOC & 1.3 & 1 & 2.09 & 13 & 23.35 & 5 & 9.78 & 4 & 7.98 & 6 & 11.96 \\
\hline total & & 100 & 100 & 100 & 100 & 100 & 100 & 100 & 100 & 100 & 100 \\
\hline grain density $^{b}\left(\mathrm{~g} / \mathrm{cm}^{3}\right)$ & & & & & & & & & & & \\
\hline
\end{tabular}

In the present work, we demonstrate that neglecting the large- $Q$ scattering part of SANS data may cause a significant underestimation of porosity, by as much as an order of magnitude. A method has been developed to extract quantitative information on size distribution of nanopores from the large- $Q$ scattering intensity.

The present study focuses on the investigation of pore morphology of the same set of New Albany Shale (Devonian/ Mississippian) samples that were previously ${ }^{4}$ analyzed using the gas adsorption and MIP techniques. The main objectives are (a) to compare porosity obtained by SANS/USANS techniques with that determined by gas adsorption and MIP; (b) to analyze microporosity values extracted from SANS and USANS data; and (c) to discuss variation of porosity with increased maturity in shale detected by SANS/USANS.

\section{EXPERIMENTAL SECTION}

2.1. Samples. The New Albany Shale samples were collected from the core material archived at the Indiana Geological Survey and the Illinois State Geological Survey. The sampling sites were carefully selected to cover a range of maturities from immature to post-mature. The mineral and chemical compositions, as well as various properties of the pore space in aliquots of these samples, were recently analyzed using organic petrology, X-ray diffraction, $\mathrm{CO}_{2}$ and $\mathrm{N}_{2}$ low-pressure adsorption, and mercury intrusion porosimetry (MIP). ${ }^{4}$ The chemical composition of shale specimens is listed in Table 1.
The classification of pore sizes used in this paper follows the classification system of the International Union of Pure and Applied Chemistry (IUPAC) ${ }^{15}$ According to IUPAC classification, pores $>50 \mathrm{~nm}$ in size are defined as macropores, whereas pores with sizes in the range of $2-50 \mathrm{~nm}$ are called mesopores. The pores $<2 \mathrm{~nm}$ in size are defined as micropores. Occasionally, we use the name "nanosized pores" to indicate small mesopores and all micropores. It is to be noted that $\mathrm{CO}_{2}$ was used to characterize micropores ( $<2 \mathrm{~nm}$ in diameter), as these pores are more accessible to $\mathrm{CO}_{2}$ than to $\mathrm{N}_{2}{ }^{4}$

2.2. SANS and USANS Experiments. SANS and USANS experiments have been carried out on coarse grain samples with a grain size of $\sim 0.5 \mathrm{~mm}$, which were loaded into aluminum sample holders with an internal thickness of $1 \mathrm{~mm}$. The size of the grains is optimized in such a way that scattering measurements provide information averaged over orientation of the grains. In addition, scattering contribution from individual grains, as well as the voids between the grains, is negligible in both the SANS and USANS regime. In addition, the effective thickness of the sample is $\sim 0.5 \mathrm{~mm}$, which helps to minimize multiple scattering. SANS experiments were conducted using the GP SANS instrument ${ }^{16}$ at Oak Ridge National Laboratory (ORNL). USANS measurements were carried out at National Institute of Standards and Technology (NIST), using the BT-5 perfect crystal SANS instrument $(\lambda=2.4 \AA) .{ }^{17}$ The slit-smeared USANS data were converted to the pinhole geometry using Lake's method. ${ }^{18}$ The experimental conditions and procedures were similar to those used in our previous studies. ${ }^{2,8}$ An approximate relationship between the scattering vector $Q\left(Q=4 \pi \lambda^{-1} \sin (\theta)\right.$, where $2 \theta$ is the scattering angle and $\lambda$ is the neutron wavelength) and the pore size $r,(r \cong 2.5 / Q)$ was used to relate the length scales in the reciprocal and real space. ${ }^{19}$ 
Table 2. Numerical Values Used in Calculations of the Scattering Length Density for Shale Component Minerals

\begin{tabular}{|c|c|c|c|c|c|}
\hline $\begin{array}{l}\text { mineral } \\
\text { name }\end{array}$ & chemical formula & $\begin{array}{l}\text { matrix density, } d \\
\left(\mathrm{~g} / \mathrm{cm}^{3}\right)\end{array}$ & $\begin{array}{l}\text { molecular weight, } M \\
(\mathrm{~g} / \mathrm{mol})\end{array}$ & $\begin{array}{c}\text { molecular scattering amplitude, } \sum s_{i} b_{i} \\
\left(\times 10^{-12} \mathrm{~cm}\right)\end{array}$ & $\begin{aligned} \mathrm{SLD} & =\left(N_{\mathrm{A}} d / M\right) \sum s_{i} b_{i} \\
& \left(\times 10^{10} \mathrm{~cm}^{-2}\right)\end{aligned}$ \\
\hline quartz & $\mathrm{SiO}_{2}$ & 2.65 & 60.085 & 1.5755 & 4.18 \\
\hline carbonates & $\mathrm{CaCO}_{3}$ & 2.80 & 100.0872 & 2.2309 & 3.76 \\
\hline albite & $\mathrm{NaAlSi}_{3} \mathrm{O}_{8}$ & 2.61 & 262.2237 & 6.595 & 3.95 \\
\hline orthoclase & $\mathrm{KAlSi}_{3} \mathrm{O}_{8}$ & 2.6 & 278.332 & 6.603 & 3.71 \\
\hline pyrite & $\mathrm{FeS}_{2}$ & 5.0 & 119.977 & 1.5234 & 3.62 \\
\hline clays & $\mathrm{Al}_{2} \mathrm{Si}_{2} \mathrm{O}_{5}(\mathrm{OH})_{4}$ & 2.63 & 263.161 & 5.2467 & 3.16 \\
\hline TOC & coal analog & 1.3 & & & 2.50 \\
\hline
\end{tabular}

Table 3. Parameters Used in the Analysis of the Five New Albany Shale Samples ${ }^{a}$

\begin{tabular}{|c|c|c|c|c|c|c|c|c|c|}
\hline $\begin{array}{l}\text { shale } \\
\text { sample }\end{array}$ & $\begin{array}{c}\text { SLD } \\
\left(\times 10^{10} \mathrm{~cm}^{-2}\right)\end{array}$ & $\begin{array}{l}\text { flat BKG } \\
\left(\mathrm{cm}^{-1}\right)\end{array}$ & $\begin{array}{l}\text { He grain density } \\
\left(\mathrm{g} / \mathrm{cm}^{3}\right)\end{array}$ & $\begin{array}{l}\text { bulk density } \\
\qquad\left(\mathrm{g} / \mathrm{cm}^{3}\right)\end{array}$ & $\begin{array}{l}\text { depth } \\
(\mathrm{m})\end{array}$ & $\begin{array}{c}\text { TOC } \\
(\text { wt } \%)\end{array}$ & $\begin{array}{l}\text { Ro } \\
(\%)\end{array}$ & $\begin{array}{l}\text { hydrogen content } \\
\text { (wt \%) }\end{array}$ & $\begin{array}{l}\text { incoherent background, } \\
\text { Inc bkgd }\left(\mathrm{cm}^{-1}\right)\end{array}$ \\
\hline $472-1$ & 3.74 & 0.5 & 2.74 & 2.49 & 61 & 1.2 & 0.35 & 0.5 & 0.027 \\
\hline MM4 & 3.39 & 0.23 & 2.3 & 2.21 & 764 & 13 & 0.55 & 3.0 & 0.16 \\
\hline NA2 & 3.57 & 0.26 & 2.56 & 2.43 & 853 & 5.3 & 0.65 & 1.4 & 0.074 \\
\hline IL-5 & 3.65 & 0.095 & 2.58 & 2.55 & 1607 & 4.3 & 1.15 & 0.6 & 0.032 \\
\hline IL-1 & 3.75 & 0.105 & 2.58 & 2.49 & 76 & 6.3 & 1.41 & 0.5 & 0.027 \\
\hline
\end{tabular}

${ }^{a}$ Helium grain density and bulk density were reported elsewhere. ${ }^{4}$ Hydrogen content and incoherent background estimated for different shale samples, from Figure 4, is also shown.

\section{RESULTS AND DISCUSSION}

3.1. Estimation of Scattering Length Density. The purpose of this section is to calculate the scattering length density (SLD) for five New Albany Shale samples (472-1, MM4, NA2, IL-5, and IL-1). Table 1 lists the proportion of mineral components and the organic matter (TOC denotes total organic carbon) in the shale samples, expressed in terms of weight percent. These numbers were converted to volume percent using the matrix density for each component, also listed in Table 1.

The neutron scattering length density was calculated for each component mineral using the formula ${ }^{14}$

$$
\rho_{n}=\frac{N_{\mathrm{A}} d}{M} \sum_{j} p_{j}\left(\sum_{i} s_{i} b_{i}\right)_{j}
$$

where $N_{\mathrm{A}}$ is Avogadro's number $\left(N_{\mathrm{A}}=6.022 \times 10^{23}\right), d$ the density, $s_{i}$ the proportion (by number) of nucleus $i$ in compound $j, p_{j}$ the proportion (by molecular number) of compound $j$ in the mixture and $b_{i}$ is the coherent scattering amplitude for nucleus $i$.

Results are presented in Table 2. As the exact composition and density for the organic matter dispersed in shales is not known, we used an estimated ${ }^{20}$ value of SLD, corresponding to a low-ash coal (with maturity VR $=0.67 \%$, similar to organic matter in shale NA2): density $=1.3 \mathrm{~g} / \mathrm{cm}^{3}, \mathrm{SLD}=2.5 \times 10^{10} \mathrm{~cm}^{-2}$.

Finally, the SLD value was calculated for each shale as a volume average over all component minerals, according to the formula

$$
\operatorname{SLD}(\text { shale })=\frac{\sum_{i}^{n} \operatorname{vol} \%(i) \operatorname{SLD}(i)}{100}
$$

where index $i$ indicates a mineral component (including TOC) and $n$ is the total number of components (including organic matter). The results are listed in Table 3.

3.2. Interpretation of SANS/USANS Results. Figure 2 shows the plot of combined SANS and USANS absolute scattering cross section $I(Q)$, given in units of $\mathrm{cm}^{-1}$, versus the scattering vector $Q$ acquired for five samples of New Albany Shale.

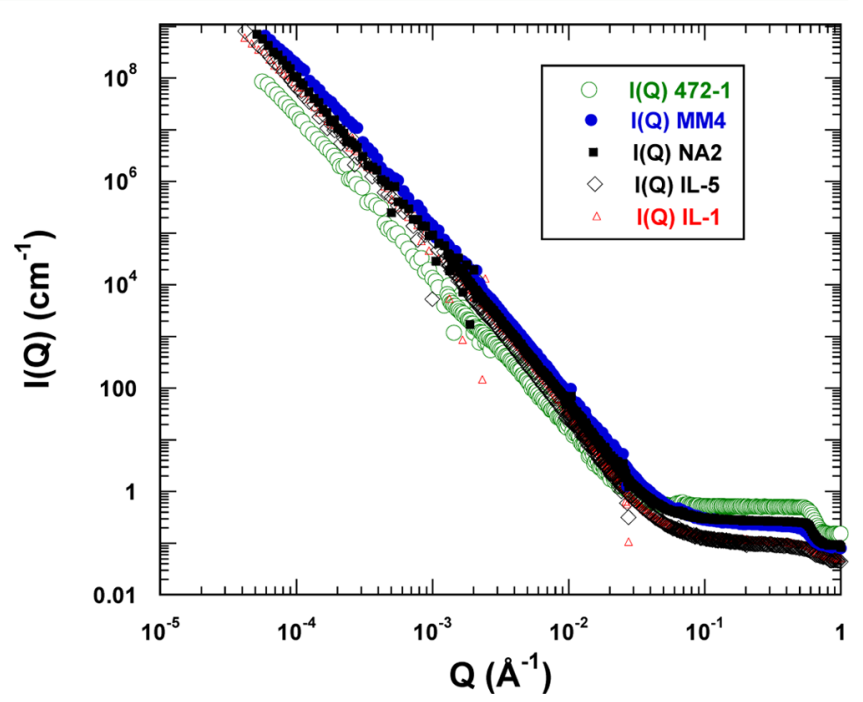

Figure 2. Combined SANS and USANS absolute scattering cross section $I(Q)$ versus the scattering vector $Q$ acquired for five samples of New Albany Shale.

The large- $Q$ end of each scattering curve has been magnified and shown in Figure 3. Figures 2 and 3 show that reliable data extend up to $Q \approx 0.5 \AA^{-1}$ only, because of the limited acceptance angle of sample holders used in this work. The scattering intensity at $Q=0.5 \AA^{-1}$, called the "flat" background, is indicated for each sample and listed in Table 3. The background for shales $472-1$ and NA2 is much larger than that typically observed for coal ${ }^{13,20}$ and is approximately an order of magnitude higher than the scattering background measured from most shales. ${ }^{2}$ We note that the high background for MM4 shale may be caused by the large content of organic matter (23.4 vol \%, see Table 1$)$.

Two possible sources of the large- $Q$ background are (1) a $Q$-independent scattering background caused by the incoherent scattering of $\mathrm{H}$ atoms bound in the organic matter and sorbed water present in the rock, and (2) scattering from microscopic inhomogeneities (e.g., pores) present in the rock matrix. The hydrogen content has been estimated ${ }^{4}$ based on the weight 


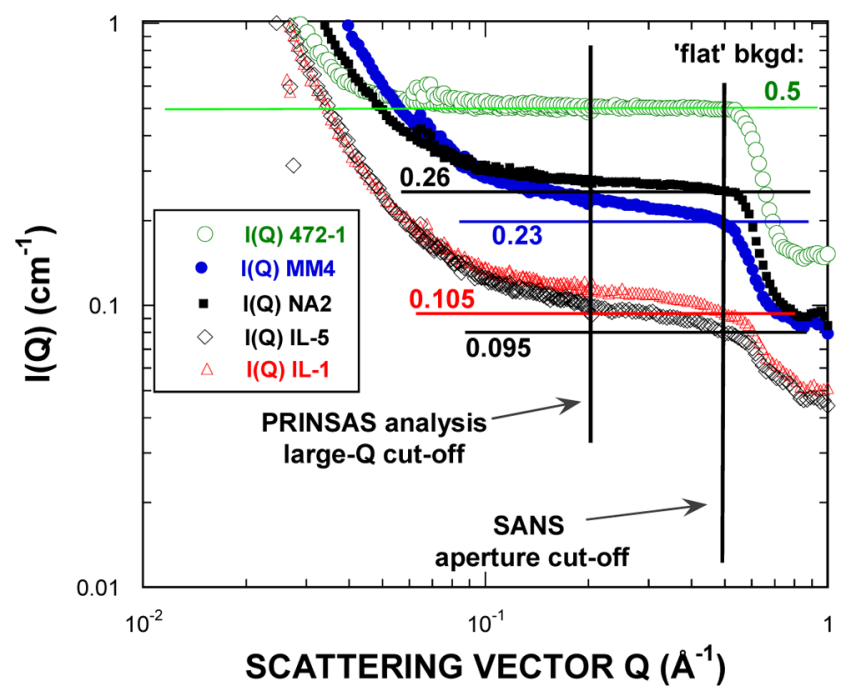

Figure 3. Large- $Q$ SANS scattering measured from five studied samples of New Albany Shale. SANS aperture and PDSP model cutoffs and the flat background for each specimen are also indicated.

percent of organic matter and is listed in Table 3. Recently, Radlinski and Radlinska ${ }^{20}$ demonstrated a correlation between hydrogen content and incoherent background, as shown in Figure 4 .

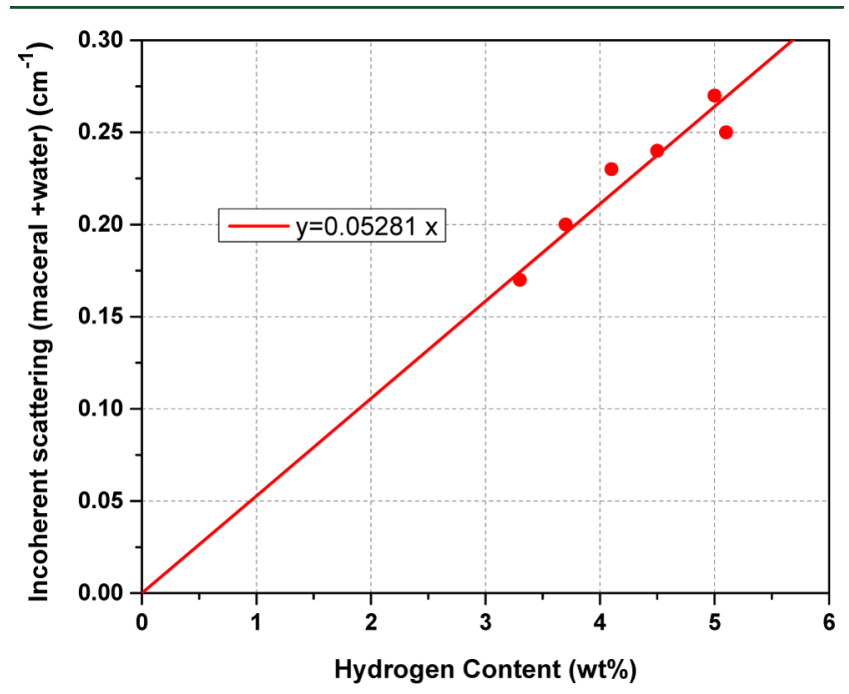

Figure 4. Correlation between the atomic hydrogen content and incoherent background used for estimation of incoherent background in New Albany Shale samples. ${ }^{20}$

As may be seen in Table 3, the estimated incoherent background due to hydrogen content in the shale specimens is significantly less than the measured flat background, except for the MM4 sample. This confirms that the measured high-Q background is not caused predominantly by the incoherent scattering. The origin of the anomalously large flat background will be discussed in detail in the following section.

The neutron scattering data were analyzed using the Polydisperse Spheres (PDSP) model, ${ }^{5}$ as implemented in PRINSAS software. ${ }^{21}$ The PDSP model assumes that the pores are three-dimensional (spherical shape is used in the PRINSAS algorithm) and may have an arbitrary size distribution. Using the calculated value of the rock matrix scattering length density (SLD), the software fits the experimental scattering curve by adjusting the pore size distribution expressed as a histogram. Total porosity and other parameters characterizing the pore space are computed from that distribution.

First, the PDSP model was fitted to as-measured SANS/ USANS $I(Q)$ curves for $Q<0.5 \AA^{-1}$, using the shale SLD and grain density values listed in Table 3 . The quality of fit was generally very good, with the exception of the large- $Q$ tail. As a first check of the validity of the PDSP model, the total porosity values generated by PRINSAS were compared with the known helium porosity values (see Table 4 ). It transpired that the

Table 4. Comparison of Porosity Values Obtained Using Various Methods for the Five New Albany Shale Samples ${ }^{a}$

$\begin{array}{lccccc}\text { se } & \begin{array}{c}\mathrm{Hg} \\ \text { porosity } \\ (\%)\end{array} & \begin{array}{c}\text { PDSP } \\ \text { porosity } \\ (\%)\end{array} & \begin{array}{c}\text { PDSP fractal } \\ \text { porosity, } \\ \begin{array}{c}0.5 \AA^{-1} \\ (\%)\end{array}\end{array} & \begin{array}{c}\text { Porage } \\ \text { porosity, } \\ Q<0.2 \AA^{-1} \\ (\%)\end{array} & \begin{array}{c}\text { average } \\ \text { fractal } \\ \text { dimension, }\end{array} \\ \text { 472-1 } & 9.1 & 5.6 & 82.8 & 0.47 & D_{\text {s }} \\ \text { MM4 } & 4.1 & 2.7 & 55.7 & 4.4 & 2.6 \\ \text { NA2 } & 5.1 & 4.1 & 55.7 & 2.64 & 2.8 \\ \text { IL-5 } & 1.5 & 0.8 & 20.4 & 1.66 & 2.8 \\ \text { IL-1 } & 3.5 & 1.4 & 21.8 & 1.79 & 2.8\end{array}$

${ }^{a} \mathrm{He}$ porosity and $\mathrm{Hg}$ intrusion porosity was calculated from the difference between grain density and bulk density measured by $\mathrm{He}$ pycnometry and $\mathrm{Hg}$ intrusion porosimetery, respectively. ${ }^{4}{ }^{b_{T}}$ The average fractal dimension $\left(D_{s}\right)$ is calculated for $Q<0.2 \AA^{-1}$ with the flat background scattering subtracted.

discrepancy between the two methods was over an order of magnitude, thus indicating that there is a significant scattering intensity component that is not well represented by the PDSP model. Thus, including in the PDSP model the flat scattering region up to $0.5 \AA^{-1}$ is not a physically viable option.

As the next step, the estimated flat background (see values listed in Table 3) has been subtracted from the experimental data. It showed that reliable (reasonably noise-free) data were then limited to $Q$-values smaller than $Q_{\max } \approx 0.2 \AA^{-1}$ (Figure 5). The scattering intensity approximately followed a power law

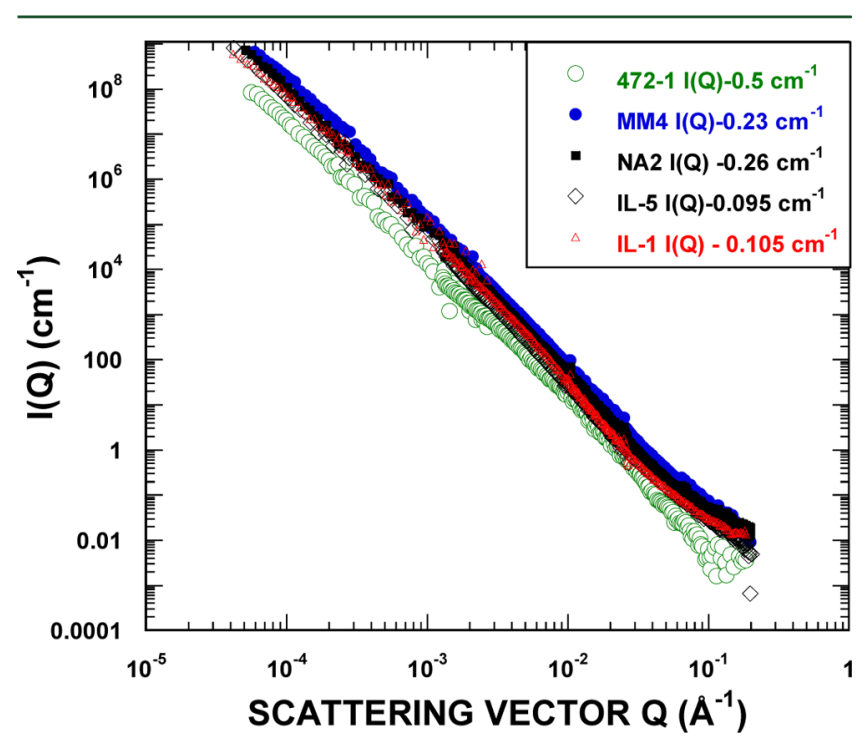

Figure 5. Combined SANS and USANS absolute scattering cross section $(I(Q))$ versus the scattering vector $(Q)$ used for the PDSP model analysis for five samples of New Albany Shale. Compared to raw data, the "flat" background has been subtracted, outlying data points removed, and the $Q$-range limited to the $Q<0.2 \AA^{-1}$ region. 
over the $Q$-range used, which is indicative of approximately fractal distribution of the pore sizes. This implies that the flat region of scattering profiles from $0.2 \AA^{-1}$ to $0.5 \AA^{-1}$ could not be represented by the PDSP model (i.e., the fractal model). In terms of real space, that $Q$-range transforms to a linear size range from $5 \AA$ to $12.5 \AA$. Thus, nanosized pores of radius within the range of 5-12.5 $\AA$ could not be represented by the fractal model.

The large- $Q$ limit $\left(Q=0.2 \AA^{-1}\right)$ for fractal-like scattering used in revised PRINSAS analysis is also highlighted in Figure 3. The PDSP model analysis was repeated using backgroundsubtracted SANS data. The quality of fit was excellent (for example, see Figure 6).

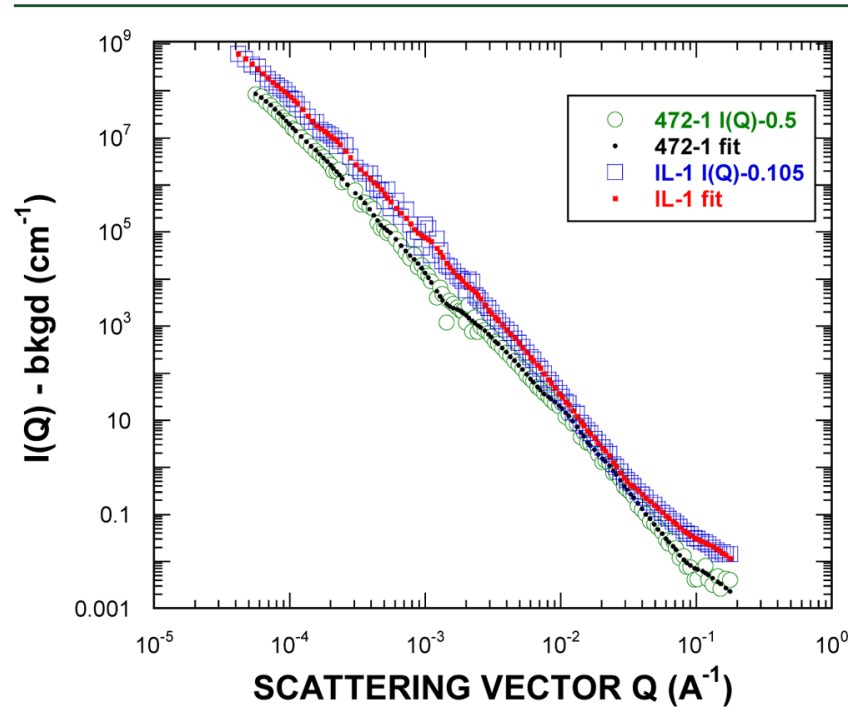

Figure 6. Illustration of the PDSP model fit for two of the New Albany Shale samples. The quality of fit for other samples is similar.

Porosities obtained by fitting the PDSP model to the background-subtracted SANS data including $Q$-values up to $0.2 \AA^{-1}$ agree better with corresponding helium porosities (see Table 4). The PDSP model porosity for the MM4 and IL-5 specimens is very close to their respective helium porosity. The least mature sample, 472-1, had particularly small PDSP porosity, compared to the helium porosity. Similarly, the estimated porosity for the NA-2 and IL-1 specimens shows a significant difference (by a factor of 2 ) from the helium porosity.

It is important, at this juncture, to mention that $\mathrm{CO}_{2}$ adsorption measurements on these shales indicate the presence of micropores $<2 \mathrm{~nm}$ in size. ${ }^{4}$ However, the PDSP model analysis does not include pores $<2.5 \mathrm{~nm}$ in size. It has also been concluded from $\mathrm{CO}_{2}$ adsorption data that the contribution to the porosity due to micropores is quite large for samples 472-1, NA2, and IL-1, compared to samples MM4 and IL-5. Therefore, it follows that the porosity calculated using the PDSP model for the former samples may be significantly underestimated, because of the exclusion of a large fraction of micropores. We also note that the scattering profile at large $Q$-values (which is dominated by the contribution from micropores) does not follow a straight line on the double logarithmic scale (see Figure 3). Hence, the size distribution of the micropores excluded from the PDSP model should not be considered fractal.

Detailed results of structural analysis for all shales (obtained using the PDSP model) are presented in the

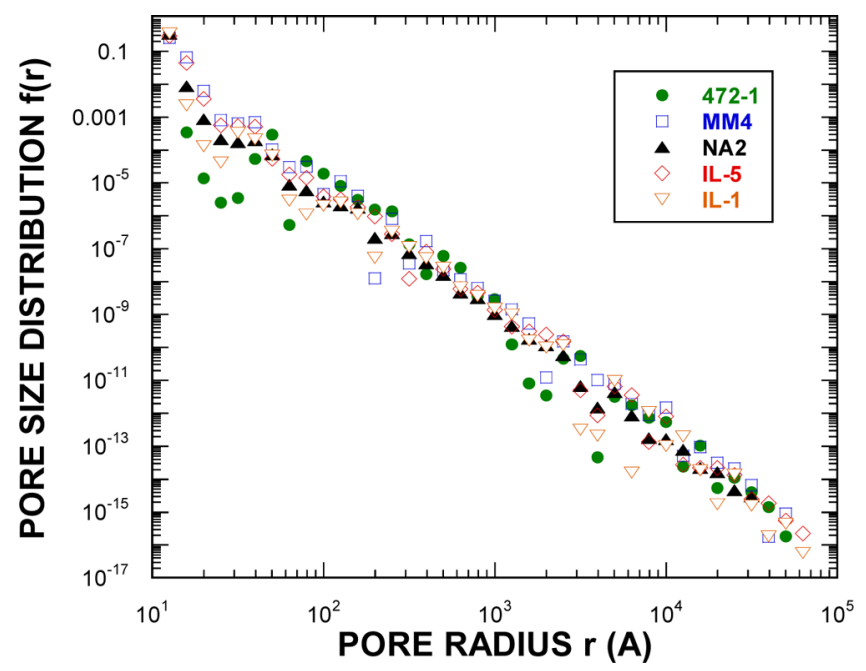

Figure 7. Pore body radius distribution calculated using the PDSD model for the fractal fraction of pores (pore radii $>1.25 \mathrm{~nm}$ ).

Supporting Information. The extracted pore radius distributions for all the specimens are shown in Figure 7. Total volume of mesopores and macropores estimated by different techniques are compared in Figures 8 and 9, respectively.

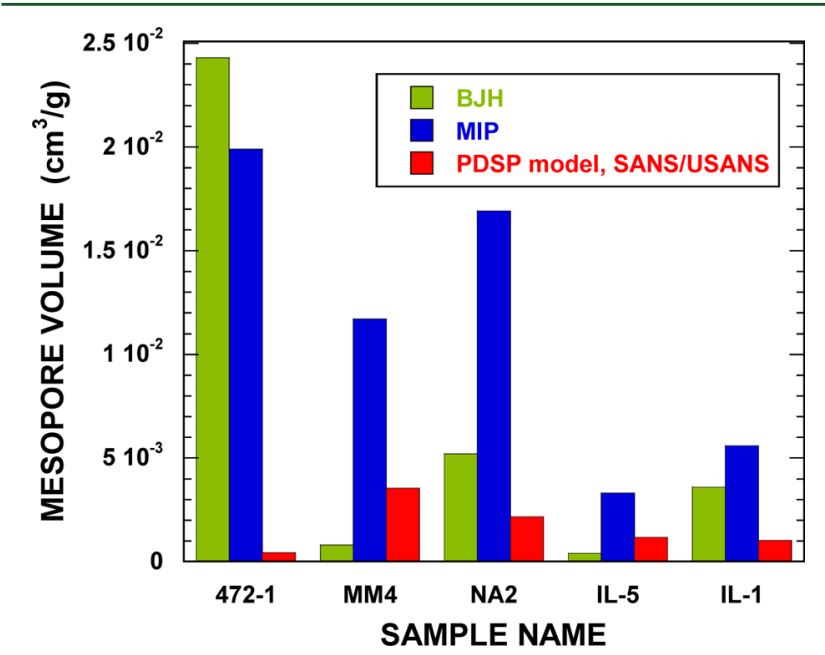

Figure 8. Mesopore volumes (pore radius $=1-25 \mathrm{~nm}$ ) for the five samples of New Albany Shale, measured using three different methods: $\mathrm{N}_{2}$ and $\mathrm{CO}_{2}$ adsorption (green), mercury intrusion porosimetry (blue), and PDSP analysis of SANS/USANS (red).

Porosity in the mesopore region estimated by SANS/USANS is low, compared to that measured by $\mathrm{N}_{2}$ adsorption and MIP method (Figure 8). This is expected since the PDSP porosity was estimated using SANS data truncated at the large- $Q$ end. Therefore, a significant population of mesopores $2-2.5 \mathrm{~nm}$ in diameter was not included in the PDSP fits. The magnitude of the underestimation is dependent on the actual number density of mesopores smaller than the cutoff size. Since the combined microporosity and mesoporosity is largest for the 472-1 shale sample, this sample also exhibits the largest discrepancy between the PDSP and sorption results. Similar reasoning can be used to interpret discrepancies observed for other samples.

In addition to the large- $Q$ SANS truncation effects, observed differences in porosities measured by gas adsorption and SANS/ USANS techniques may be partly attributed to (1) existence of micropores not described well by the PDSP model and, 


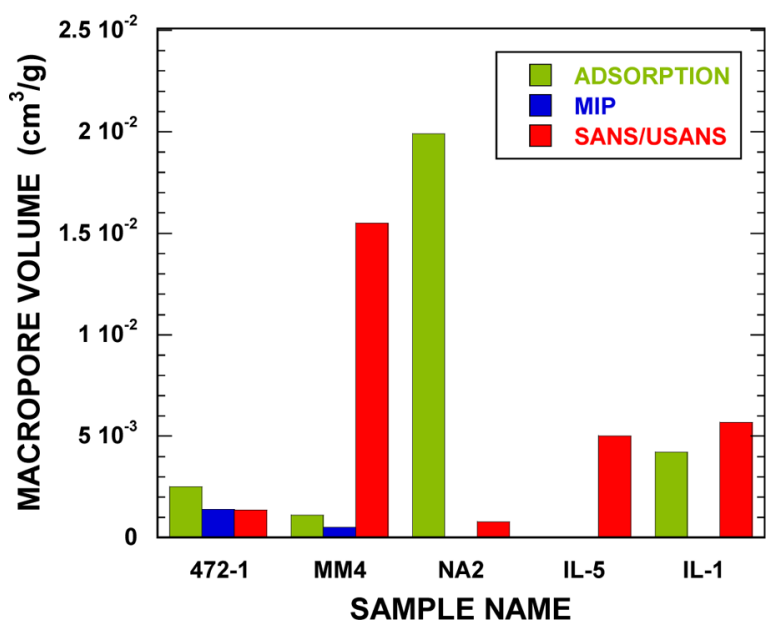

Figure 9. Macropore volumes (pore radius $>25 \mathrm{~nm}$ ) for the five samples of New Albany Shale, measured using three different methods: $\mathrm{N}_{2}$ and $\mathrm{CO}_{2}$ adsorption (green), mercury intrusion porosimetry (blue), and PDSP analysis of SANS/USANS (red).

importantly, (2) $\mathrm{N}_{2}$ and $\mathrm{CO}_{2}$ fluid condensation in the smallest micropores.

Total pore volumes of macropores, estimated using various techniques, are shown in Figure 9. Macropore volumes for the 472-1 and IL-1 shale samples are in generally good agreement with each other. However, the macropore volume estimated by SANS/USANS analysis for shale MM4 is large, compared to MIP and adsorption data, which may be due to the presence of significant number of pores that are not accessible to the invading fluids. For the NA2 shale sample, the macropore volume determined by adsorption is large, compared to that estimated by SANS/USANS. This is a puzzling result, which could be possibly explained by different pore geometry assumed in the analysis of the adsorption and scattering data.

3.3. Porosity Calculations using Porod Invariant. The model-independent Porod invariant method has been applied to estimate the porosity of shale samples. For a two-phase system (rock matrix and the pore space), the porosity $(\phi)$ can be calculated from the Porod invariant, $Q_{\mathrm{inv}}$ :

$$
Q_{\text {inv }}=\int_{0}^{\infty} Q^{2} I(Q) \mathrm{d} Q=2 \pi^{2}(\Delta \rho)^{2} \phi(1-\phi)
$$

The value of the integral is sensitive to the precision with which the scattering intensity has been determined, which, in turn, is strongly affected by the choice of the large- $Q$ scattering background. This is demonstrated in Table 5, which shows (1) a

Table 5. Porosity Values Estimated Using Porod Invariant (PI) and PDSP Model for the Same Large-Q Background

\begin{tabular}{|c|c|c|c|c|c|}
\hline sample & $\begin{array}{c}\text { near-fractal } \\
\text { large- } Q \\
\text { background } \\
\left(\mathrm{cm}^{-1}\right)\end{array}$ & $\begin{array}{c}\text { PDSP } \\
\text { porosity } \\
(\%)\end{array}$ & $\begin{array}{c}\text { PI } \\
\text { porosity } \\
(\%)\end{array}$ & $\begin{array}{l}\text { helium } \\
\text { porosity } \\
(\%)\end{array}$ & $\begin{array}{c}\text { He porosity } \\
\text { compatible } \\
\text { large- } Q \\
\text { background } \\
\left(\mathrm{cm}^{-1}\right)\end{array}$ \\
\hline $472-1$ & 0.50 & 0.47 & 0.699 & 9.1 & 0.455 \\
\hline MM4 & 0.23 & 4.4 & 4.05 & 4.1 & 0.23 \\
\hline NA-2 & 0.26 & 2.64 & 3.22 & 5.1 & 0.25 \\
\hline IL-5 & 0.095 & 1.66 & 1.58 & 1.5 & 0.095 \\
\hline IL-1 & 0.105 & 1.79 & 1.92 & 3.5 & 0.090 \\
\hline
\end{tabular}

${ }^{a_{T}}$ The He porosity compatible background is the background that is subtracted from the experimental scattering profile to achieve the helium porosity in the Porod Invariant method. comparison of porosity calculated using the polydisperse sphere (PDSP) model and the Porod Invariant method (with the same large- $Q$ background determined assuming a near-fractal scattering, as illustrated in Figure 3 and listed in Table 5) and (2) an estimated value of the large- $Q$ background needed to match the independently measured helium porosity value for each sample.

Table 5 shows that the porosities computed using the PDSP model and Porod Invariant method for the same background are similar to each other, as expected. Comparison of the nearfractal large- $Q$ background and the He-porosity-compatible background values (columns 2 and 6, Table 5) and of the corresponding porosity values (columns 4 and 5, Table 5) well illustrates high sensitivity of the estimated porosity to the corresponding value of the large- $Q$ background.

3.4. The Origin of the Large- $Q$ Background. The large- $Q$ background values measured in this work cannot be solely attributed to the incoherent scattering on hydrogen nuclei bound in the organic component of the rock matrix. Figure 10 illustrates

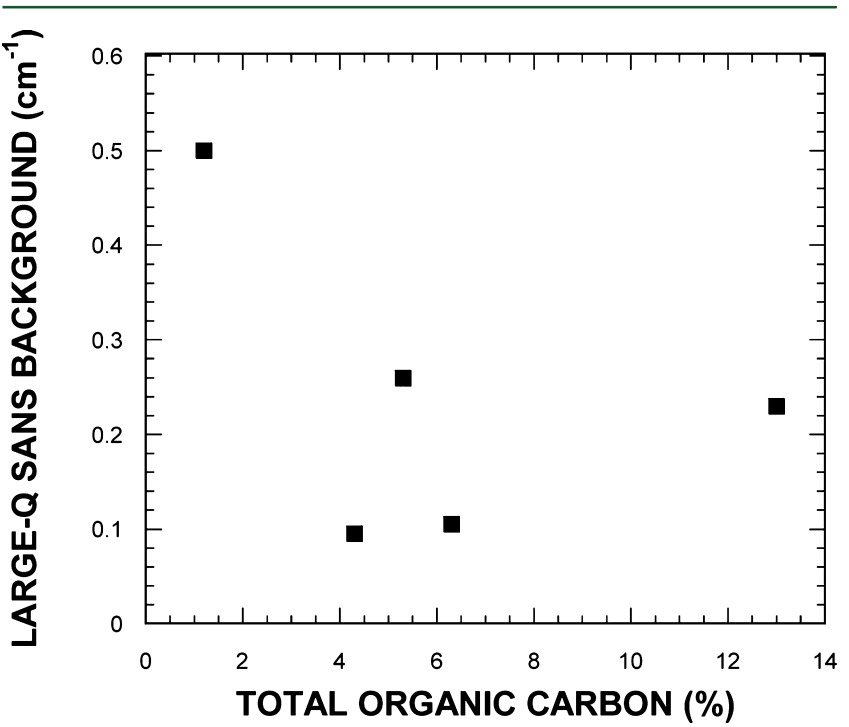

Figure 10. Cross-plot of scattering intensity at $Q=0.5 \AA^{-1}$ (large- $Q$ background) and total organic matter content (TOC in units of wt \%) for five shales.

that there is no positive correlation between the intensity of large- $Q$ background and organic matter content (TOC) in the five shales, which proves the point. Such a conclusion is to be expected, since, at the quantitative level, the incoherent scattering intensity for a low-ash coal of a similar density and chemical composition of the organic matter can be calculated as $1 / 20$ of the weight percentage of hydrogen: ${ }^{19}$

$$
I(\text { incoh })\left[\mathrm{cm}^{-1}\right] \approx 0.053(\mathrm{H}[\mathrm{wt} \%])
$$

Using hydrogen content values listed in Table 3, the incoherent scattering intensity (also listed in Table 3 ) can be shown to be small (but not insignificant), compared to the measured SANS background for each shale sample (see Table 3).

Looking at the porosity data listed in Table 4, it appears that (within experimental error of roughly $\pm 0.1 \%$ ) the helium porosity usually matches or exceeds the PDSP model (SANS/USANS) porosity. Assuming that $\mathrm{He}$ gas molecules can penetrate all pores taken into account in our analysis of SANS and USANS (i.e., pores larger than $\sim 12.5 \AA$ in body radius), one can assign the difference between the He porosity and PDSP porosity (excess porosity, or nonfractal porosity, $\left.\Phi_{\mathrm{ex}}\right)$ to very small nanopores 
(body radius $<12.5 \AA$ ). Scattering from these nanopores contributes to the large- $Q$ background, in addition to scattering from closed nanopores and the incoherent background.

In order to test the above hypothesis, the excess porosity $\Phi_{\mathrm{ex}}$ is plotted as a function of the large- $Q$ scattering background (Figure 11). There is some scatter in the data, but the fitted line suggests the following approximate relationship:

$$
\Phi_{\mathrm{ex}}=-2.2+20 \times \mathrm{bkgd}
$$

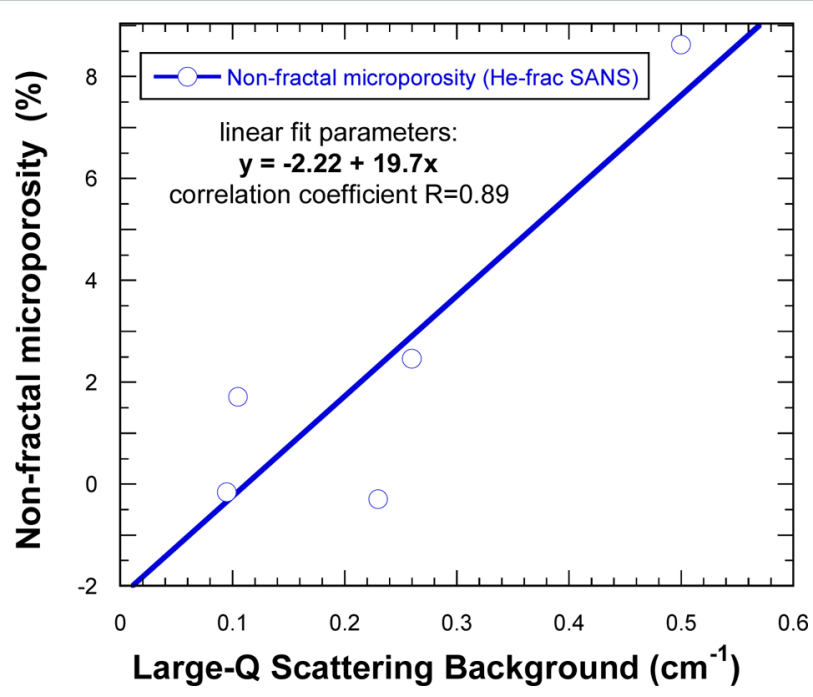

Figure 11. Cross-plot of the excess total porosity $\Phi_{\mathrm{ex}}$ versus scattering intensity at $Q=0.5 \AA^{-1}$ (large- $Q$ scattering background). Excess porosity is dominated by micropores of linear body size smaller than $12.5 \AA$ and unknown shape and origin. The fitted line suggests the following approximate relationship: $\Phi_{\mathrm{ex}}=-2.2+20 \times \mathrm{bkgd}$, where $\Phi_{\text {ex }}$ is expressed as a percentage and the "flat" background (bkgd) is given in terms of $\mathrm{cm}^{-1}$.

where $\Phi_{\text {ex }}$ is expressed as a percentage and bkgd is the background (in $\mathrm{cm}^{-1}$ ). We can understand the above observation as follows. There are some closed (inaccessible to helium fluid) nanopores, which (together with the incoherent scattering) give rise to a scattering background component of $0.11 \mathrm{~cm}^{-1}$. Any scattering above this level is caused by helium-accesssible (open) pores. The large-Q SANS results available to us (almost flat background only) provides no information about the geometry of these pores.

Going one step farther, one can estimate the incoherent scattering intensity using the approach outlined in Figure 4 and Table 3. The incoherent free background (if_bkgd) can be estimated by subtracting the incoherent contribution from the large- $Q$ background. The excess microporosity $\left(\Phi_{\mathrm{ex}}\right)$ has been shown in Figure 12 as a function of the incoherent free background. The linear fit is markedly improved compared to Figure 11, and the approximate relationship between $\Phi_{\mathrm{ex}}$ and if_bkgd is

$$
\Phi_{\text {ex }}=-1.2+20.5 \times \text { if_bkgd }
$$

where $\Phi_{\text {ex }}$ is expressed as a percentage and if bkgd is given in terms of $\mathrm{cm}^{-1}$. The scattering component of He-inaccessible pores only (without the incoherent component), for which $\Phi_{\mathrm{ex}}=0$, can be estimated as $0.059 \mathrm{~cm}^{-1}$. Any scattering above that value is caused by accessible nonfractal nanopores. The described procedure provides a method of estimating the nonfractal nanoporosity value (called microporosity in the

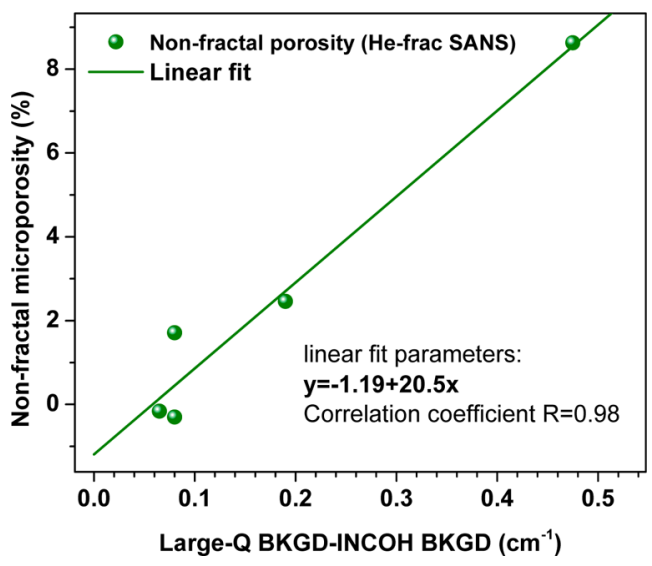

Figure 12. Cross-plot of the excess total porosity $\left(\Phi_{\mathrm{ex}}\right)$ versus scattering intensity at $Q=0.5 \AA^{-1}$ with the incoherent background subtracted. Fitted line suggests the approximate relationship: $\Phi_{\text {ex }}=$ $-1.2+20.5 \times$ if bkgd, where $\Phi_{\text {ex }}$ is expressed as a percentage and the incoherent-free background (if_bkgd) given in terms of $\mathrm{cm}^{-1}$.

organic geochemistry literature) from the measurements of large- $Q$ background, at least for the New Albany Shale rocks.

3.5. Trends in Shale Porosity as a Function of Maturity. Finally, the total porosity and microporosity of shale specimens was analyzed as a function of sample maturity. Figure 13a illustrates the apparent correlation between the total porosity and the incoherent-free fraction of the large- $Q$ background versus thermal maturity of the organic matter (expressed in terms of vitrinite reflectance), whereas Figure 13b shows the apparent correlation between the PDSP porosity and the incoherent-free fraction of the large- $Q$ background versus thermal maturity of the organic matter.

The porosity decreases generally with increasing maturity of the organic matter. This is expected, as thermal maturity is a proxy for the depth of burial (achieved at some time between the deposition and the present time), and the larger depth of burial leads to more-pronounced compaction of the rock matrix. However, this general trend can be modified by the processes related to the organic matter transformation and hydrocarbon generation, as was suggested for this set of samples in the previous study. ${ }^{4}$ The fact that the incoherent-free large- $Q$ background decreases in step with the total helium porosity strongly suggests that the background is most likely caused by the (compaction-affected) nanosize porosity rather than the shortrange inhomogeneity of the chemical composition of the rock matrix. Correlation between the microporosity and the large- $Q$ background is not that clear-cut when the PDSP porosity, rather than helium porosity, is used (Figure 13b). However, this may simply be a consequence of the approximate procedure by which the large- $Q$ background has been determined (the nearfractality assumed for the $I(Q)$ function), which is subject to the particularly large uncertainty for the largest measured background (for sample $472-1$, Ro $=0.35 \%$, in this case).

3.6. Estimates of the Size and Number Density of Nanopores Contributing to the Large- $Q$ Background. In this section, we estimate the range of size, as well as the number density of micropores (using the IUPAC classification), both accessible and inaccessible to $\mathrm{He}$ fluid, that contribute to the large- $Q$ scattering background. We assume that (i) the nanosized pores are three-dimensional, dilute, and isotropic, and (ii) they are roughly monodisperse in size for each rock sample. 

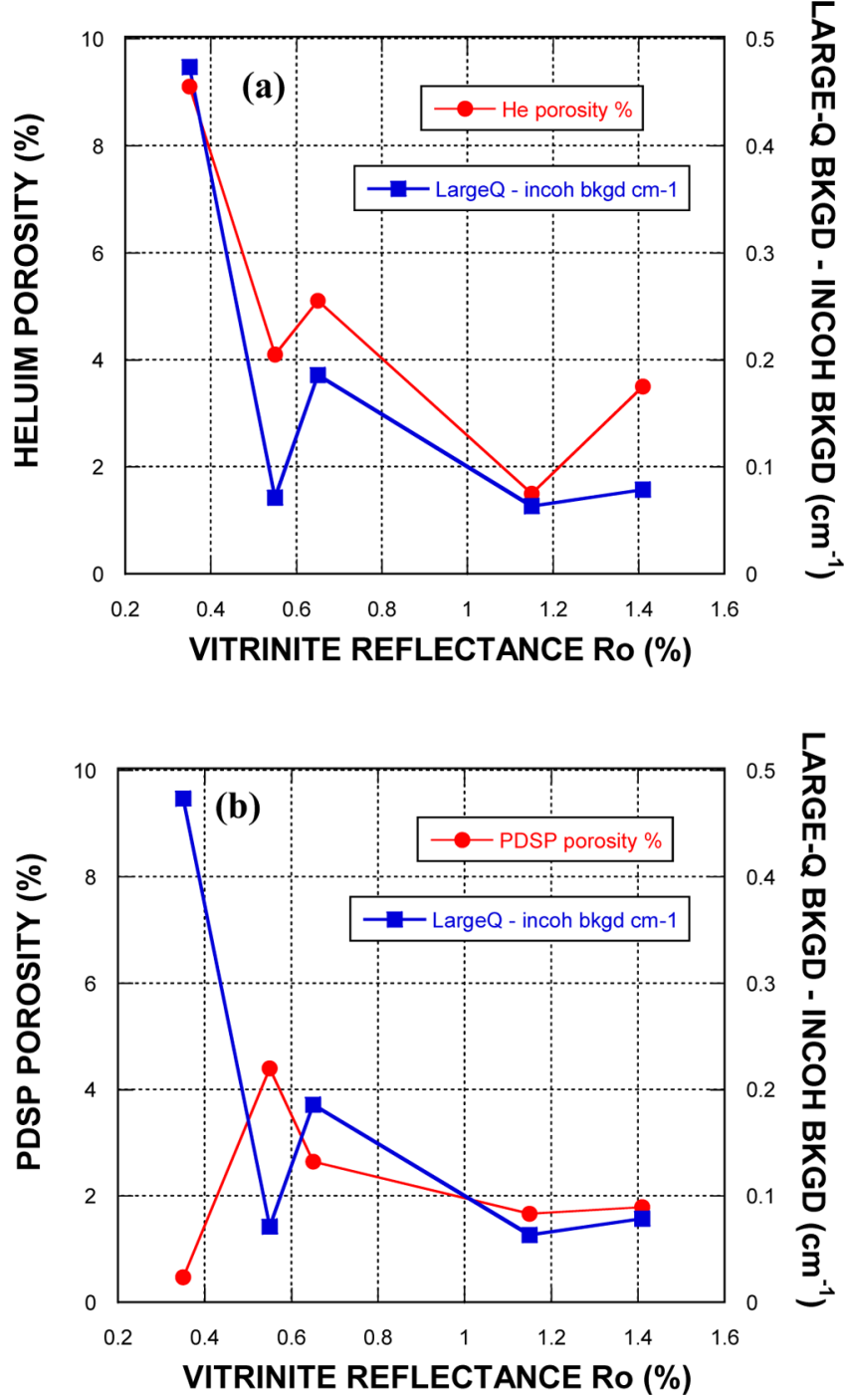

Figure 13. (a) Incoherent-free background and total porosity, as a function of shale maturity. (b) Incoherent-free background and PDSP porosity, as a function of shale maturity.

According to the Guinier law, for $Q R_{\mathrm{g}} \ll 1$ scattering from such a system is given by

$$
I(Q)=n(\Delta \rho V)^{2} \exp \left[-\frac{Q^{2} R_{g}{ }^{2}}{3}\right] \approx n(\Delta \rho V)^{2}\left[1-\frac{Q^{2} R_{g}{ }^{2}}{3}+\cdots\right]
$$

where $n$ is the number density of the scatterers of volume $V$ (in units of $\mathrm{cm}^{-3}$ ), $\Delta \rho$ is the scattering contrast and $R_{\mathrm{g}}$ is the radius of gyration of the scatterers. We assume that the nearly flat scattering intensity $\left(I_{0}\right)$, observed for all samples at the large $Q$-values $\left(Q \geq 0.4 \AA^{-1}\right.$, see Figure 3) corresponds to the sum of the incoherent scattering $\left(I_{\text {incoh }}\right)$ and the saturation value of the Guinier region for the nanosize scatterers $\left(I\left(Q_{\text {sat }}\right)\right)$. The notation $I\left(Q_{\text {sat }}\right)$ indicates nanopore scattering intensity at some $Q$-value, such that (1) $Q \ll 1 / r_{\mathrm{ns}}$ and (2) the contribution of scattering from the larger pores (e.g., fractal scattering) is negligible, where $r_{\mathrm{ns}}$ is the radius of the micropore.

According to eq 2 , the saturation value for the nanosized pore scattering is

$$
I\left(Q_{\text {sat }}\right)=n(\Delta \rho V)^{2}
$$

Since the numerical values of both $I\left(Q_{\text {sat }}\right) \approx[($ large- $Q$ bkgd $)-$ $\left.I_{\text {incoh }}\right]$ and $\Delta \rho$ are known (Table 3), eq 3 describes a relationship between the estimated scatterer radius $(r)$ (calculated here from $\left.V=4 \pi r^{3} / 3\right)$ and the number of scatterers per unit volume $(n)$ for each sample. Since the fraction of sample volume occupied by scatterers (i.e., sample porosity, $\Phi$ ) is $n V$, it is convenient to rearrange eq 3 into the following form:

$$
I\left(Q_{\text {sat }}\right)=n V(\Delta \rho)^{2} \frac{4}{3} \pi r^{3}=\Phi(\Delta \rho)^{2} \frac{4}{3} \pi r^{3}
$$

Equation 4 can be used to create a plot of porosity versus scatterer radius and narrow down the range of possible (monodisperse) scatterer sizes (see Figure 14).

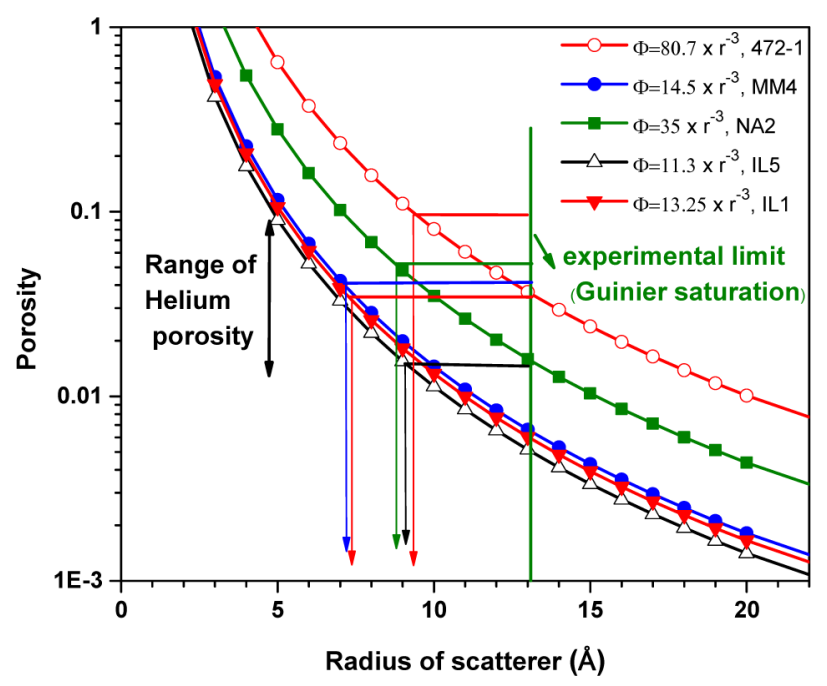

Figure 14. Graphic representation of the theoretically allowed porosity values versus the monodisperse scatterer size. For detailed description see text.

In Figure 14, five different symbols are used to show the relationship between the scatterer size and the number of scatterers (expressed as the porosity, $\Phi=n V$ ), which is consistent with the incoherent-free scattering intensity, $I\left(Q_{\text {sat }}\right)$, measured for the five samples of New Albany Shale. The colorcoded horizontal lines indicate the helium porosity value for each sample. The intersection of such line with the curve interpolated between symbols corresponding to the same sample determines the minimum radius of hypothetical monodisperse nanopores, as indicated with color-coded vertical arrows. In reality, the nanopores account for only a (unknown) fraction of the total helium porosity; therefore, the scatterer radii must be larger than their minimum values indicated in Figure 14. On the other hand, the nano-scatterer radius cannot be larger than $2 \pi / 0.5 \approx 12.5 \AA$, since the $I(Q)$ curves presented in Figure 3 seem to be fully saturated for every sample at the experimental upper limit of the $Q$-range, equal to $Q=0.5 \AA^{-1}$. The experimental Guinier saturation limit is indicated in Figure 14 with a vertical green line. It follows from Figure 14 that the large- $Q$ SANS data are consistent with the existence of nanopores with linear sizes (radii) within the range of 7-13 $\AA$ for the MM4 and IL-1 samples, and 9-13 Å for the 472-1, NA2, and IL-5 samples. In principal, SANS detection of scatterers of such sizes is possible; however it requires access to scattering data at $Q$-values much larger than those accessible in our experiments.

Since the fraction of total porosity contained in micropores is not precisely known, one can only gain a limited insight into 
Table 6. Nanoporosity and Number Density of Nanopores Calculated According to Scenarios 1 and $2^{a}$

\begin{tabular}{|c|c|c|c|c|c|c|}
\hline sample & $\begin{array}{l}\text { helium } \\
\text { porosity } \\
\text { (\%) }\end{array}$ & $\begin{array}{c}\text { nanopore } \\
\text { radius, } \mathrm{r}(\AA)\end{array}$ & $\begin{array}{l}\text { single nanopore volume, } \\
4 \pi r^{3} / 3\left(\times 10^{-21} \mathrm{~cm}^{3}\right)\end{array}$ & $\begin{array}{l}\text { nanopore number density, }{ }^{n} \\
(\text { Scenario } 1)\left(\times 10^{19} \mathrm{~cm}^{-3}\right)\end{array}$ & $\begin{array}{l}\text { nano-porosity for } \\
r=12 \AA(\%)^{c}\end{array}$ & $\begin{array}{c}\text { nanopore number density, } n \\
(\text { Scenario } 2)\left(\times 10^{18} \mathrm{~cm}^{-3}\right)\end{array}$ \\
\hline $472-1$ & 9.1 & 9.7 & 3.8 & 2.4 & 4.7 & 6.5 \\
\hline MM4 & 4.1 & 7.0 & 1.44 & 2.85 & 0.86 & 1.2 \\
\hline NA2 & 5.1 & 8.9 & 2.95 & 1.73 & 2.1 & 2.9 \\
\hline IL-5 & 1.5 & 9.2 & 3.26 & 0.46 & 0.66 & 0.91 \\
\hline IL-1 & 3.5 & 7.4 & 1.7 & 2.06 & 0.77 & 1.1 \\
\hline
\end{tabular}

${ }^{a}$ Single nanopore volume for $r=12 \AA$ is $7.24 \times 10^{-21} \mathrm{~cm}^{3}$. For details, see text. ${ }^{b}$ Helium porosity is defined as being equal to $n V$. ${ }^{c}$ Calculated from background data corresponding to the right-hand-side ordinate in Figure 13.

the number density $(n)$ of nanopores. Based on the relationship illustrated in Figure 14, Table 6 lists estimates of the value of $n$ for two scenarios: (1) total helium porosity is contained in monodisperse nanopores of radius $r$ and (2) all nanopores are monodisperse and have the same radius for every shale sample (12 $\AA$ ), which is close to the maximum possible radius consistent with our data. This estimate is done for illustrative purposes only.

It follows that the number density of nanopores in the New Albany Shale samples may vary from $\sim 1 \times 10^{18} \mathrm{~cm}^{-3}$ to $\sim 3 \times 10^{19} \mathrm{~cm}^{-3}$, assuming that pores are three-dimensional and roughly monodisperse (see Table 6). Figure 15 illustrates the

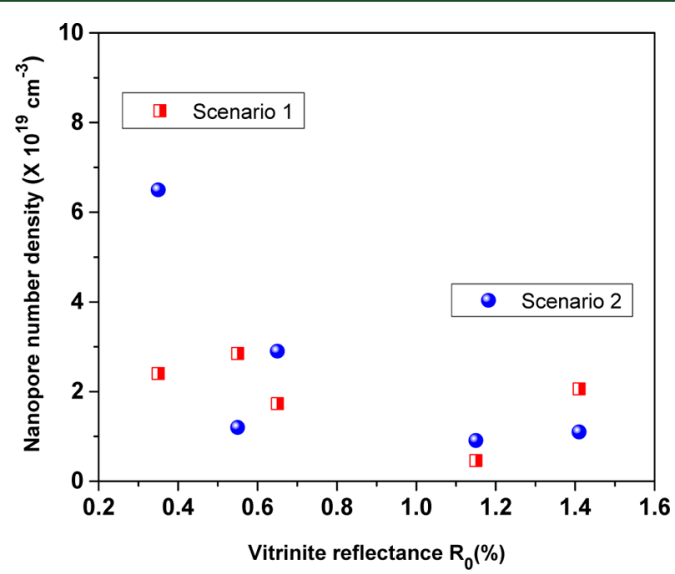

Figure 15. Number density of micropores calculated according to Scenario 1 and Scenario 2, plotted versus the thermal maturity of organic matter, for five New Albany Shale samples. Ordinate values for Scenario 2 data points are multiplied by a factor of 10 .

correlation between the nanopore number density and the thermal maturity of organic matter for the five samples according to the two scenarios.

Comparing these results with the $\mathrm{CO}_{2}$ adsorption data presented in Figure 17 of ref 4, Scenario 1 (monodisperse nanopores of shale-specific size) appears to be more plausible than Scenario 2.

\section{CONCLUSIONS}

SANS results indicate that pores in the New Albany Shale samples can be categorized as fractal and nonfractal, depending on the pore size. Macropores $(>50 \mathrm{~nm})$ and the majority of mesopores $(2-50 \mathrm{~nm})$ are surface fractals and their structure is well-represented by the PDSP model. In the mesopore region, the total porosity computed from SANS/USANS data significantly differs from that determined by gas adsorption and MIP technique, most likely because of the exclusion of significant population of mesopores, owing to truncation of neutron scattering data. Other factors, such as the possible condensation of invading fluid in nanosized pores and the assumption of a specific pore geometry, may also play a role. SANS results suggest that for the immature to post-mature shales microporosity is highest in the least-mature samples and decreases with shale maturity. At the same time, microporosity may increase slightly for post-mature shale. Scattering from nonfractal micropores $(<2 \mathrm{~nm})$ contributes significantly to the high-Q flat background. A newly developed method of analysis allows extracting qualitative information on the structure of micropores (such as the size range and number density) from the background. The method is general and may provide information on the morphology of nanosized pores in natural and engineered porous systems.

\section{ASSOCIATED CONTENT}

\section{S Supporting Information}

Detailed results of PDSP modeling of the structure of five shale samples are presented as Supporting Information. The data include variation of the internal specific surface area as a function of probe size (Figure S1), incremental pore volume $\mathrm{d} V / \mathrm{d} r$ (Figure S2) and the cumulative pore volume (Figure S3). All results were obtained using SANS/USANS data in the Q-range from $5 \times 10^{-5} \AA^{-1}$ to $0.2 \AA^{-1}$. This material is available free of charge via the Internet at http://pubs.acs.org.

\section{AUTHOR INFORMATION}

\section{Corresponding Author}

*Tel.: +1 865576 7746. E-mail: melnichenkoy@ornl.gov.

\section{Notes}

The authors declare no competing financial interest.

\section{ACKNOWLEDGMENTS}

The authors would like to acknowledge D. F. R. Mildner for his help during USANS experiments. The research at Oak Ridge National Laboratory's High Flux Isotope Reactor was sponsored by the Laboratory Directed Research and Development Program and the Scientific User Facilities Division, Office of Basic Energy Sciences, U.S. Department of Energy. This research was supported in part by the ORNL Postdoctoral Research Associates Program, administered jointly by the ORNL and the Oak Ridge Institute for Science and Education. This study was also partly supported by U.S. Department of Energy, Office of Science, Office of Basic Energy Sciences, under Grant Award No. DE-SC0006978 (formerly No. DEFG02-11ER16246). This work utilized facilities supported in part by the National Science Foundation, under Agreement No. DMR-0454672. We acknowledge the support of the National Institute of Standards and Technology, U.S. Department of 
Commerce, in providing the neutron research facilities used in this work.

\section{REFERENCES}

(1) Chalmers, G. R.; Bustin, R. M.; Power, I. M. AAPG Bull. 2012, 96, 1099-1119.

(2) Clarkson, C. R.; Freeman, M.; He, L.; Agamalian, M.; Melnichenko, Y. B.; Mastalerz, M.; Bustin, R. M.; Radlinski, A. P.; Blach, T. P. Fuel 2012, 95, 371-385.

(3) Clarkson, C. R.; Solano, N.; Bustin, R. M.; Bustin, A. M. M.; Chalmers, G. R. L.; He, L.; Melnichenko, Y. B.; Radliński, A. P.; Blach, T. P. Fuel 2013, 103, 606-616.

(4) Mastalerz, M.; Schimmelman, A.; Drobniak, A.; Chen, Y. AAPG Bull. 2013, 97, 1621-1643.

(5) Radlinski, A. P.; Mastalerz, M.; Hinde, A. L.; Hainbuchner, M.; Rauch, H.; Maron, M.; Lin, J.-S.; Fan, L.; Thiyagarajan, P. Int. J. Coal Geol. 2004, 59, 245-271.

(6) Melnichenko, Y. B.; He, L.; Sakurovs, R.; Kholodenko, A. L.; Blach, T.; Mastalerz, M.; Radlinski, A. P.; Cheng, G.; Mildner, D. F. R. Fuel 2012, 91, 200-208.

(7) Mastalerz, M.; He, L.; Melnichenko, Y. B.; Rupp, J. A. Energy Fuels 2012, 26, 5109-5120.

(8) Ruppert, L. F.; Sukurovs, R.; Blach, T. P.; He, L.; Melnichenko, Y. B.; Mildner, D. F. R.; Alcantar-Lopez, L. Energy Fuels 2013, 27, 772779.

(9) Nelson, P. H.; Batzle, M. L. Single-phase permeability. In General Engineering; Fanchi, J., Ed.; Petroleum Engineering Handbook, Vol. I: Society of Petroleum Engineers (SPE): Richardson, TX, 2006; pp 687-726.

(10) Nelson, P. H. AAPG Bull. 2009, 93, 329-340.

(11) Bustin, R. M.; Bustin; A. M. M.; Cui, X.; Ross, D. J. K.; Murthy Pathi, V. S. Presented at the 2008 SPE Shale Gas Production Conference, Fort Worth, TX, USA, Nov. 16-18, 2008; Society of Petroleum Engineers: Richardson, TX, 2008; SPE Paper No 119892 (DOI: 10.2118/119892-MS).

(12) Kuila, U.; Prasad, M. Presented at the 2011 SPE Annual Technical Conference and Exhibition, Denver, CO, USA, Oct. 30-Nov. 2, 2011; SPE Paper No 146869 (http://www.spe.org/atce/2011/ pages/schedule/tech_program/documents/spe146869\%201.pdf).

(13) Jin, L.; Rother, G.; Cole, D. R.; Mildner, D. F. R.; Duffy, C. J.; Brantley, S. L. Am. Mineral. 2011, 96, 498-512.

(14) Radlinski, A. P. Small Angle Neutron Scattering and Rock Microstructure. In Neutron Scattering in Earth Sciences; Wenk, H.-R., Ed.; Reviews in Mineralogy and Geochemistry, Vol. 63; 2006; Chapter 14, pp 363-397.

(15) Orr, C. Surface area measurement. In Analytical Chemistry in Industry, Vol. 4; Kolthoff, I. M., Elving, P. J., Stross, F. H., Eds.; Treatise on Analytical Chemistry: Part III; John Wiley and Sons: New York, 1977; pp 321-358.

(16) Wignall, G. D.; Littrell, K. C.; Heller, W. T.; Melnichenko, Y. B.; Bailey, K. C.; Lynn, G. W.; Myles, D. A.; Urban, V. S.; Selby, D. L. J. Appl. Crystallogr. 2012, 45, 990-998.

(17) Barker, J. G.; Glinka, C. J.; Moyer, J. J.; Kim, M. H.; Drews, A. R.; Agamalian, M. J. Appl. Crystallogr. 2005, 38, 1004-1011.

(18) Lake, J. A. Acta Crystallogr. 1967, 23, 191-194.

(19) Radlinski, A. P.; Boreham, C. J.; Lindner, P.; Randl, O.; Wignall, G. D.; Hinde, A.; Hope, J. M. Org. Geochem. 2000, 31, 1-14.

(20) Radlinski, A. P.; Radlinska, E. Z. The microstructure of pore space in coals of different rank: A small angle scattering and SEM study. In Coalbed Methane: Scientific, Environmental and Economic Evaluation; Mastalerz, M., Glikson, M., Golding, S. D., Eds.; Kluwer Academic Publishers: Dordrecht, The Netherlands, 1999; pp 329365.

(21) Hinde, A. L. J. Appl. Crystallogr. 2004, 37, 1020-1024. 